\title{
OS BACHARÉIS EM DIREITO NA REFORMA DO JUDICIÁRIO técnicos ou curiosos?
}

\author{
Maria Tereza Sadek \\ Professora do Departamento de Ciência Política da USP e Pesquisadora do Idesp \\ Humberto Dantas \\ Cientista Social, Pesquisador da Fundação Instituto de Pesquisas Econômicas da FEA-USP
}

\begin{abstract}
Resumo - O artigo aponta a continuidade de uma tendência que teve início no século passado: a predominância de bacharéis em Direito na Câmara dos Deputados. Praticamente todos os partidos com representação no Legislativo - independentemente de sua posição no espectro ideológico - possuem em suas fileiras um grande número de advogados. Este traço também não distingue nenhuma região do país. Além disso, o predomínio de bacharéis em Direito foi critério adotado pelos partidos para a constituição da Comissão encarregada da reforma do Poder Judiciário.

Palavras-chave: Bacharéis em Direito; Câmara dos Deputados; Comissão de Reforma e Poder Judiciário.
\end{abstract}

\begin{abstract}
"Reforma do Judiciário não é matéria para curioso. $\dot{E}$ para quem tem autoridade no tema. Eu a tenho, exatamente por ser advogado e professor de direito Constitucional."
\end{abstract}

Michel Temer, Presidente da Câmara dos Deputados 15 de junho de 1999

"O presidente da Câmara não deveria intrometer-se na reforma do Judiciário, até por que é um advogado (...) e não pretende que sejam descobertas imoralidades."

Antônio Carlos Magalhães, Presidente do Senado 15 de junho de 1999

$\mathrm{N}$ o dia 5 de outubro de 1988, o país retomou seu compromisso com a democracia, promulgando sua sétima Constituição e optando por um regime representativo, presidencialista e federativo. Cinco anos mais tarde (1993), porém, estava prevista uma revisão constitucional. Tal iniciativa - de todo inusitada poderia abalar a credibilidade e a previsibilidade do regime, qualidades fundamentais para o pleno funcionamento de um Estado baseado em normas. Dentre as propostas de mudança constitucional, o Título IV, "Da Organização dos Poderes”, em seu Capítulo III, “Do Poder Judiciário", foi o que recebeu o maior número de emendas (exatamente 3.917), configurando-se em alvo privilegiado das iniciativas de reformas. Do ponto de vista dos resultados efetivos, no entanto, a revisão da Constituição esteve longe de atingir os objetivos de seus proponentes. O Judiciário saiu dos trabalhos de revisão constitucional incólume, reforçando a opinião de que se trata de uma área refratária a mudanças. Muitas das alterações sugeridas, contudo, já eram ou transformaram-se, separadamente, em Propostas de Emenda Constitucional - PECs. ${ }^{1}$

A PEC número 96-A, relativa ao Poder Judiciário, tramita no Congresso desde 1992, tendo recebido alterações em 1995 e 1996. Recentemente, voltou a ser considerada fundamental para o pleno desenvolvimento de nosso regime democrático, após quatro anos de obsequioso esquecimento. Uma CPI - Comissão Parlamentar de Inquérito - foi instalada no Senado, com o objetivo de investigar casos de nepotismo, corrupção e mal desempenho de um poder visto como "encastelado" e, conseqüentemente, alertar para a necessidade de uma reforma rápida e abrangente. Ao mesmo tempo, uma Comissão Especial para discussão das reformas judiciárias na Constituição foi formada na Câmara dos Deputados. Disputas acirradas envolveram tais iniciativas, sendo que os conflitos não se circunscreveram às duas casas do Legislativo. Autoridades do Executivo, do Judiciário e lideranças da sociedade civil perfilaram-se, transformando os inegáveis problemas que atingem a justiça brasileira em escusas para suas causas.

A intenção, neste artigo, não é discutir os resultados da CPI e tampouco o teor das modificações propostas pela Emenda Constitucional. O objetivo aqui é muito mais 
restrito: mapear o perfil profissional dos integrantes da Câmara dos Deputados, fazendo especial referência aos 31 parlamentares que compõem a Comissão Especial encarregada de introduzir modificações na estrutura e no funcionamento do Poder Judiciário. A hipótese defendida aqui é a de que, apesar da atual diversidade na composição profissional dos integrantes do poder Legislativo, ainda é bastante significativa a presença de bacharéis em Direito, sobretudo quando se trata de indicar os representantes para uma Comissão incumbida de propor alterações no poder Judiciário. Esta análise preocupa-se, primeiramente, com o número de deputados formados em Direito nesta Comissão; em seguida, será apontada a continuidade de uma tendência iniciada em meados do século passado e mantida até os dias de hoje, isto é, o alto índice de bacharéis de Direito na composição da Câmara dos Deputados. Para esta discussão estar-se-á, de alguma forma, enfrentando os termos das acusações trocadas entre os presidentes da Câmara e do Senado. Ainda que a questão da participação ou não de bacharéis em Direito seja o aspecto menos relevante da disputa protagonizada pelos presidentes das duas casas do Legislativo, ela oferece a oportunidade de elaborar um retrato do Legislativo e de verificar se para os diferentes partidos a reforma do Judiciário deve ser liderada por advogados ou por "curiosos".

\section{CURSOS JURÍDICOS: DA INTENÇÃO AO ACASO}

Os cursos jurídicos surgiram no Brasil, durante o Império, com a clara intenção de formar nossa elite dirigente. Julgava-se que a independência política exigiria igual autonomia cultural. Esta estratégia implicava a transferência de Coimbra e de outros centros europeus para o interior do país das escolas responsáveis pela "cabeça" dos que ocupariam os postos de mando. Assim, foram criados cursos jurídicos estritamente controlados pelo governo central. ${ }^{2}$ Apesar de dirigidos para os jovens das famílias que ocupavam os mais altos postos na hierarquia econômica, eram inteiramente gratuitos, financiados pelo poder público, com a justificativa de que respondiam a um interesse nacional e não privado.

As primeiras faculdades foram instaladas em Olinda (PE) e em São Paulo (SP), ${ }^{3}$ visando formar uma elite capaz de dirigir o país recém-independente e preparada para construir um Estado Nacional. Ao lado da titulação acadêmica profissional, as faculdades de Direito constituíram-se em campo fértil de discussões políticas, culturais e sociais. Desta forma, o Largo de São Francisco, em São Paulo, e a Faculdade de Direito, em Olinda, transformamse em conceituados centros intelectuais, devido primordialmente aos seus docentes e estudantes. $\mathrm{O}$ apogeu desta época "dourada" deu-se em 1860, quando a quantidade de revistas literárias, bibliotecas, livrarias e outros cursos das mais diversas disciplinas modificaram o ritmo das provincianas cidades. Ilustres foram os alunos que freqüentaram o curso jurídico. Citam-se, como exemplos, os nomes de Álvaro de Azevedo, Bernardo Guimarães, José de Alencar, Castro Alves, Joaquim Nabuco, Rui Barbosa, Olavo Bilac, entre outros (Bruno, 1953).

Em pouco tempo, os diplomados pelas faculdades de Direito começaram a marcar presença no cenário político nacional. Carvalho (1974) mostra o contraste na composição da Assembléia antes e depois da instalação dos cursos jurídicos no país. Em 1826, do total de deputados, $1 \%$ equivalia a advogados, $8 \%$ a bacharéis e $27 \%$ a magistrados, perfazendo um total de $36 \%$ de formados em Direito. Em 1886, após a implantação dos cursos jurídicos em São Paulo e Olinda, são visíveis os efeitos da política educacional adotada: $12 \%$ são advogados, $46,4 \%$ são bacharéis e $6,4 \%$ são magistrados, totalizando $64,8 \%$. O crescente aumento na participação desses profissionais contracena com a diminuição dos cidadãos oriundos de outras áreas acadêmicas e/ou profissionais, particularmente as ciências exatas e a medicina. A expressiva participação política dos bacharéis não se dava apenas na Câmara. Carvalho (1974) aponta que, enquanto em $182661 \%$ dos senadores provinham da área do direito, em 1831 este percentual subiu para 71\%, em 1840 para 78\%, em 1853 para $93 \%$ e em 1871 para $72 \%$. No que se refere aos ministros, os diplomados em Direito compreendiam 51\% em $1822,57 \%$ em $1831,85 \%$ em 1840, $77 \%$ em 1853 e $86 \%$ em 1871.

Durante o século XX, entretanto, nota-se uma expressiva mudança no papel das Faculdades de Direito e no perfil de seus diplomados. Primeiramente, os cursos deixaram de ser estritamente controlados e financiados pelo Estado e perderam a característica de centros formadores de homens destinados, sobretudo, à política e à alta administração pública. Se no século passado existiam apenas dois cursos jurídicos no Brasil, ao longo dos últimos 98 anos este número evoluiu significativamente. Para ilustrar a proliferação de escolas desta natureza, pode-se citar como exemplo o Estado de São Paulo. No século XIX, havia somente a escola do Largo São Francisco, mantendo-se este quadro inalterado até o início da década de 40. 
Em 1946 foi fundado o curso jurídico da PUC - Pontifícia Universidade Católica de São Paulo - e durante a década de 50 foram criadas outras sete escolas, localizadas no interior e no litoral. Nos anos 60 , devido à política de incentivos do governo militar à abertura de cursos superiores, houve o surgimento de 16 novos centros no Estado. Entre os anos 70 e 80, foram abertas mais 12 faculdades, seis em cada década. Por fim, entre 1990 e 1994, mais dez novos cursos de Direito foram inaugurados. ${ }^{4}$

Este aumento na quantidade de escolas ${ }^{5}$ certamente tem a ver com o crescimento da população, com a urbanização, com a ampliação do acesso à educação, dentre outros fatores. O mercado, para o bacharel em Direito, é bastante amplo, caracterizando-se pela opção de atuação no setor privado ou pelo exercício de carreiras ligadas ao Estado - juízes, promotores, procuradores, defensores públicos e delegados. Este cenário, aparentemente promissor, propiciou o surgimento de cursos deficientes, despejando enorme contingente de bacharéis, muitas vezes malpreparados, no mercado de trabalho. Indubitavelmente, estas novas Faculdades e seus "novos profissionais" alteraram a imagem da categoria, que deixou de ser a do "bacharel-oligarca", do "homem ilustrado". A grande massa dos egressos das Faculdades de Direito vem enfrentando, inclusive, dificuldades para o exercício de seu ofício. A carreira tem mostrado claros sinais de corrosão, e o estudante, depois de cinco anos de faculdade, encontra-se longe de gozar do prestígio que usufruía antes da proliferação destes cursos. Tal situação foi percebida na década de 70, quando a Ordem dos Advogados do Brasil, ${ }^{6}$ preocupada em minimizar os efeitos da proliferação dos cursos, com o nível do ensino jurídico e em manter o controle sobre o mercado profissional, instituiu o Exame de Ordem como condição indispensável para o exercício da profissão de advogado. Em 1994 a entidade conquistou o controle monopolístico sobre a única forma de ingresso na carreira de advogado. Esta decisão provocou o surgimento de bacharéis marginalizados, ou seja, impossibilitados de atuar no setor privado por terem sido reprovados no exame. Da mesma forma, aqueles que optam pelas carreiras públicas - juiz, promotor, procurador, defensor público e delegado - têm esbarrado em concursos que exigem dos candidatos um saber que vem inviabilizando o preenchimento desses cargos, pela imensa maioria dos inscritos nos processos de seleção. ${ }^{7}$ Afastados da possibilidade de ingresso em uma carreira relacionada ao seu curso, milhares de bacharéis em Direito buscam outras alternativas.
Muitas escolas passaram a ser caracterizadas como "faculdades de fachada" ou "cursos de fim-de-semana" (Castro, 1999), restando a seus formandos a procura aos chamados "cursinhos", que prometem "milagres" e fácil aprovação em qualquer um dos concursos anteriormente citados. Além disso, a matrícula nestes cursos "auxiliares" tem feito aumentar ainda mais o investimento necessário para a habilitação profissional para atuação no mercado de trabalho. Inauguram-se, assim, mais um estágio para a formação profissional e mais uma forma de obtenção de lucros. Ou seja, para além das despesas com mensalidades, matrículas, material didático, acrescenta-se o que é despendido com as inscrições em exames e concursos. ${ }^{8}$ A frequiência a estes cursos aumenta as chances de exercício de uma atividade relacionada ao curso de Direito. Deve-se ressaltar que alunos oriundos de boas faculdades (conceito A no exame do Ministério da Educação) têm obtido altos índices de aprovação nos exames de Ordem. Entretanto, mesmo estes bacharéis, quando optam pela carreira pública, não costumam se livrar dos referidos "cursinhos preparatórios".

\section{OS BACHARÉIS EM DIREITO NA CÂMARA DOS DEPUTADOS}

Como já apontado, apesar de ser crescente o número de diplomados em Direito, seu prestígio encontra-se em franco declínio. À diminuição das chances de sucesso no mercado de trabalho, contudo, não tem correspondido igual ausência nos postos de mando. De fato, tais profissionais continuam a ocupar lugar de destaque na política nacional, mostrando, deste ponto de vista, ser menor a distância com a situação da segunda metade do século passado. A presença de bacharéis, sobretudo na Câmara de Deputados, ainda é marcante. Ao contrário, porém, dos bacharéis do século XIX, oriundos de cursos que visavam especialmente o preparo para o exercício político, o cenário verificado no final do século XX parece ser distinto. Os dados disponíveis não permitem supor que entre os objetivos das faculdades de Direito destaque-se ainda a formação de homens destinados ao desempenho de cargos legislativos e executivos. Mesmo assim, observase que, apesar das alterações nas características acadêmicas, em 1982, por exemplo, 60,6\% dos deputados federais eram formados em Direito. Em 1986 este percentual caiu para $35 \%$ e, em 1995 , para $30,4 \%$, ou seja, quase um terço do total da Câmara. Em junho de 1999, aproximadamente $28 \%$ dos parlamentares formaram-se em cursos 
jurídicos. É indiscutível o declínio na proporção de bacharéis no conjunto dos deputados, mas esta é ainda a profissão majoritária entre os parlamentares.

Teriam estes profissionais alguma peculiaridade em sua atuação no Legislativo? A volta da discussão sobre a reforma do Poder Judiciário no Brasil pode se constituir em uma oportunidade para a abordagem desta questão. A Constituição permite que o presidente da República e os participantes das mais altas instâncias da Justiça proponham mudanças na lei constitucional. Entretanto, são os deputados e senadores os responsáveis fundamentais por tais modificações. Quando foi composto o grupo encarregado da reforma do Poder Judiciário, que critério foi utilizado pelos diferentes partidos? Isto é, esteve presente a necessidade de participação de profissionais que tenham maior afinidade com esta área? Do ponto de vista dos objetivos das alterações - tornar o Judiciário mais eficiente no cumprimento de suas funções - nada indicaria, em princípio, que apenas bacharéis em Direito teriam condições de propor mudanças. Mesmo porque caberia aos deputados, mais do que discussões técnicas, ouvir diferentes setores da sociedade e concluir sobre instrumentos e mecanismos aptos a aperfeiçoar o sistema de Justiça.

Veja-se, por exemplo, o tema do embate entre o presidente da Câmara, deputado Michel Temer, e o presidente do Senado, Antônio Carlos Magalhães, ocorrido de maneira mais ríspida em junho de 1999. O primeiro mostrou-se favorável a uma comissão para reforma do Judiciário formada por bacharéis em Direito e o segundo posicionou-se contra, alegando corporativismo e desinteresse deste grupo na aprovação de medidas que pudessem colocar em risco vantagens propiciadas pelo atual sistema legal e judicial.

A Tabela 1 mostra a composição da Comissão de Reforma do Judiciário, evidenciando que, assim como seu presidente, os membros da Câmara dos Deputados ou pelo menos as lideranças partidárias, de alguma forma, concordam com a tese segundo a qual a reforma do Poder Judiciário é assunto para acadêmicos do Direito. Nota-se que, dos 31 parlamentares que integram esta Comissão Especial, 28 são formados em cursos jurídicos, ou seja, 90\% de seus componentes. Restam três parlamentares: um militar, um empresário e, um engenheiro que acumula a atividade de professor universitário.

A extraordinária predominância de bacharéis em Direito na Comissão não é proporcional à presença destes profissionais nem na Câmara nem nos distintos partidos. O percen- tual de diplomados em Direito na Comissão é três vezes maior (90\%) do que aquele observado na Câmara (28\%). Tal composição demonstra uma total confiança da Câmara na assunção de que os bacharéis em Direito seriam, realmente, os parlamentares mais qualificados para dirigirem as mudanças no poder Judiciário.

TABELA 1

Parlamentares da Comissão para Reforma do Poder Judiciário, segundo Qualificação

Brasil - 1999

\begin{tabular}{lrr}
\hline \multirow{2}{*}{ Qualificação } & \multicolumn{2}{c}{ Deputados } \\
\cline { 2 - 3 } & Nos Abs. & $\%$ \\
\hline \multirow{2}{*}{ Total } & 31 & 100,0 \\
Formados apenas em Direito & 12 & 38,7 \\
Formados em Direito e com Outras Profissões & 16 & 51,6 \\
Detentores de Outros Diplomas (sem o Direito) & 3 & 9,7 \\
\hline
\end{tabular}

Fonte: Site da Câmara dos Deputados na Internet (www.camara.gov.br).

Nota-se que, dos 28 deputados com formação superior em Direito, 16 possuem outras ocupações (um deles registra, inclusive, acumular as atividades de procurador de Justiça e professor), enquanto os outros 12 são exclusivamente advogados ou diplomados em Direito.

As comissões são formadas respeitando-se a proporcionalidade partidária existente na Câmara. Dessa forma, cabe investigar a presença de advogados no interior de cada legenda partidária. No Quadro 1, apresentam-se a profissão, o partido e a unidade federativa de cada um dos 31 parlamentares que compõem a comissão encarregada de propor reformas para o poder Judiciário.

O PFL, o PT, o PPB, o PTB e o PDT, ocupando diferentes posições no espectro ideológico, ${ }^{9}$ contribuem com um total de 17 deputados. Todos estes parlamentares possuem formação superior em Direito. Os outros dois partidos representados na comissão, o PMDB e o PSDB, cada um com seis representantes, preenchem dez de seus postos com bacharéis. O PSDB completou sua cota com um empresário, enquanto o PMDB nomeou um militar para a vaga restante. Entre os pequenos partidos, distinguindo-se as legendas consideradas de esquerda das de direita, nota-se que nas de esquerda existe um representante e este com curso superior em Direito, enquanto no bloco de direita o único parlamentar é engenheiro e professor universitário.

Em todos estes partidos, convém ressaltar, não existe tal supremacia de parlamentares oriundos da área do Direito. Se a Comissão fosse formada ao acaso, have- 
ria uma chance de aproximadamente $28 \%$ dos integrantes da Comissão ostentarem diploma em curso superior em Direito. No entanto, observa-se que $90 \%$ deste grupo têm esse título acadêmico. Este desvio pode ser mais bem aquilatado quando analisada a proporcionalidade existente no interior de cada partido. Caso tal proporção fosse respeitada, tanto o PT como o PPB deveriam enviar para a Comissão apenas um bacharel em Direito. Porém, todas as sete vagas desses partidos são ocupadas por diplomados em direito. O PDT, o PTB e os pequenos blocos - de direita e esquerda - deveriam, somados, ter apenas um parlamentar formado em cursos jurídicos na Comissão; entretanto, das cinco vagas disponíveis para este grupo, quatro são ocupadas por bacharéis. Por fim, PFL, PSDB e PMDB deveriam nomear, cada um, dois deputados formados em Direito, mas a realidade é bem diferente: das 19 cadeiras na Comissão destinadas a estas legendas, 17 são ocupadas por deputados detentores de diplomas em cursos jurídicos.
Verifica-se, ainda, através do Quadro 1, a falta de proporcionalidade no que diz respeito à unidade federativa em que o parlamentar se elegeu. $\mathrm{O}$ dado que mais chama a atenção refere-se ao Estado da Bahia, que possui aproximadamente $7 \%$ dos deputados da Câmara, mas na comissão contribui com quase $13 \%$ dos parlamentares, ou seja, quatro nomes. Metade destes deputados é filiada ao PFL, partido que tem no Presidente do Senado, o baiano Antônio Carlos Magalhães, sua maior figura de expressão. Os outros dois representantes pertencem ao PT e ao PSDB. O Estado de São Paulo, unidade federativa do presidente da Câmara, Michel Temer, ocupa o maior número de vagas (precisamente seis), correspondendo a $19 \%$ da Comissão, contra $13,5 \%$ de representantes paulistas no total de deputados federais. Porém, quando estes dados são agrupados por regiões do país, como mostra a Tabela 2, percebe-se um maior equilíbrio. As maiores distorções no interior da Comissão são verificadas na região Sudeste, com $7 \%$ acima de sua real proporção na Câmara, e na região Sul, com um déficit de 5\%.

\section{QUADRO 1}

Parlamentares da Comissão de Reforma do Judiciário, por Qualificação

e Estado, segundo Partido Político

Brasil - 1999

\begin{tabular}{|c|c|c|c|c|c|}
\hline Bacharel de Direito & Outra Profissão & Estado & Bacharel em Direito & Outra Profissão & Estado \\
\hline PFL & & & PT & & \\
\hline Sim & Sim & SC & Sim & Sim & RJ \\
\hline Sim & Não & BA & Sim & Não & SP \\
\hline $\mathrm{Sm}$ & Sim & SP & Sim & Não & SE \\
\hline Sim & Sim & TO & Sim & Sim & $\mathrm{BA}$ \\
\hline Sim & Sim & BA & & & \\
\hline Sim & Sim & RN & PDT & & \\
\hline Sim & Sim & $\mathrm{PI}$ & Sim & Não & SP \\
\hline PMDB & & & PSDB & & \\
\hline Não & Militar & DF & Sim & Não & SP \\
\hline Sim & Não & RJ & Sim & Sim & $M G$ \\
\hline Sim & Sim & PA & Sim & Não & $\mathrm{BA}$ \\
\hline Sim & Não & RS & Não & Empresário & CE \\
\hline Sim & Não & GO & Sim & Sim & CE \\
\hline Sim & Sim & SC & Sim & Não & SP \\
\hline PPB & & & PTB & & \\
\hline Sim & Sim & $\mathrm{PA}$ & Sim & Não & SP \\
\hline Sim & Sim & $M G$ & Sim & Não & RJ \\
\hline Sim & Sim & RJ & & & \\
\hline PSB/PCdoB & & & PL/PST/PMN/PSD/PSL & & \\
\hline Sim & Sim & MA & Não & Engenheiro Eletr. & $M G$ \\
\hline
\end{tabular}

Fonte: Site da Câmara dos Deputados na Internet (www.camara.gov.br). 


\begin{tabular}{lcc}
\hline \multicolumn{3}{c}{$\begin{array}{c}\text { Distribuição dos Bacharéis em Direito na Comissão e na Câmara, } \\
\text { segundo Regiões } \\
\text { Brasil - 1999 }\end{array}$} \\
\hline Regiões & \multicolumn{2}{c}{ Bacharéis em Direito } \\
\cline { 2 - 3 } & Na Comissão & Na Câmara \\
\hline Sudeste & 42,0 & 35,0 \\
Sul & 10,0 & 15,0 \\
Norte & 10,0 & 13,0 \\
Nordeste & 32,0 & 29,5 \\
Centro-Oeste & 6,0 & 8,0 \\
\hline
\end{tabular}

Fonte: Site da Câmara dos Deputados na Internet (www.camara.gov.br).

Voltando à discussão acerca das carreiras representadas na Câmara, a Tabela 3 reproduz a divisão percentual das atividades profissionais dos deputados federais. Deve-se ressaltar que apenas as ocupações de 512 parlamentares estão sendo consideradas, uma vez que o site da Câmara na Internet (www.camara.gov.br) não traz nenhuma referência ao $53^{\circ}$ representante do Estado de Minas Gerais. Deste total, 143 são formados em Direito, ou seja, 27,9\%. Ressalte-se que muitos parlamentares têm mais de uma ocupação, o que faz com que o total some mais de $100 \%$. Dentre os representantes analisados, foram encontradas 811 atividades, ou seja, uma média 1,6 por deputado federal.

Percebe-se que, apesar de em proporção inferior à verificada nas legislaturas anteriormente citadas (1982, 1986 e 1995), os bacharéis em Direito - sejam delegados, procuradores, advogados ou cidadãos exercendo outras profissões ainda que formados em Direito - ainda detêm o maior percentual profissional dentro da Câmara (27,9\%). Até mesmo a ocupação de professor, que permite o exercício simultâneo de outras profissões, tem uma menor proporção de deputados $(21,7 \%)$. Saliente-se, também, a presença de $21,5 \%$ de empresários, industriais e comerciantes e de $16,6 \%$ de economistas, administradores e contadores.

Em tese, todos os grupos profissionais arrolados na Tabela 3 teriam interesse na reforma do Poder Judiciário e, certamente, poderiam ocupar lugar na referida Comissão. Estudos recentes, voltados para a relação entre justiça e economia, mostram que a morosidade da Justiça e a complexidade de nossas leis são os principais entraves para a entrada de capital externo no Brasil, seja no que diz respeito à instalação de indústrias e busca de parcerias, seja para o investimentos no mercado financeiro (Pinheiro, 1996). Além disso, o crescente descontentamento com o desempenho da Justiça, o aumento da criminalidade e a descrença da população nos órgãos ligados ao Poder Judiciário são indicadores de que a questão Justiça ultrapassa as fronteiras estritas do Direito.

A Tabela 4 possibilita uma análise mais acurada de como os parlamentares formados em cursos jurídicos distribuemse em relação às suas profissões. Nota-se, como havia sido dito anteriormente, que um número considerável desses políticos exerce outras atividades, muitas relacionadas com o diploma acadêmico e outras distantes ou muito remotamente ligadas a esta formação acadêmica.

TABELA 3

Deputados Federais, segundo Profissões

Brasil - 1999

\begin{tabular}{lcc}
\hline \multirow{2}{*}{ Profissões } & \multicolumn{2}{c}{ Deputados Federais } \\
\cline { 2 - 3 } & Nos Abs. & $\%$ \\
\hline Direito & 143 & 27,93 \\
Professor & 111 & 21,68 \\
Empresário - Industrial - Comerciante & 110 & 21,48 \\
Economista - Administrador - Contador & 85 & 16,60 \\
Atividades Ligadas à Agropecuária & 77 & 15,04 \\
Médico - Dentista & 68 & 13,28 \\
Engenheiro & 46 & 8,98 \\
Jornalista - Radialista & 38 & 7,42 \\
Funcionário Público & 26 & 5,08 \\
Bancário & 15 & 2,93 \\
Pastor & 15 & 2,93 \\
Não Informaram & 7 & 1,37 \\
Outros Profissionais & 70 & 13,67 \\
\hline
\end{tabular}

Fonte: Site da Câmara dos Deputados na Internet (www.camara.gov.br).

TABELA 4

Parlamentares da Câmara Federal Formados em Direito, segundo Profissões Brasil - 1999

\begin{tabular}{lcc}
\hline \multirow{2}{*}{ Bacharéis em Direito na Câmara } & \multicolumn{2}{c}{ Deputados } \\
\cline { 2 - 3 } & Nos Abs. & $\%$ \\
\hline Formado Somente em Direito & 56 & 39,0 \\
Bacharel em Direito ou Advogado & 53 & \\
Delegado & 2 & \\
Promotor & 1 & \\
Formado em Direito e com Outras Atividades & 87 & 61,0 \\
Mais uma Profissão & 60 & \\
Mais duas Profissões & 20 & \\
Mais três Profissões & 6 \\
Mais quatro Profissões & 1 & \\
Distribuição das "Outras Profissões" & & \\
Professor & 33 \\
Empresário & 23 \\
Radialista & 6 \\
Jornalista & 6 \\
Contador & 8 \\
Atividade Agropecuária & 10 \\
Outras & 36 \\
\hline
\end{tabular}

Fonte: Site da Câmara dos Deputados na Internet (www.camara.gov.br). 
Dos 143 deputados formados em Direito, 56 (39\%) têm apenas uma profissão. Desses, três seguiram carreira pública, sendo dois delegados e um promotor. Os outros 53 são advogados. Os demais 87 parlamentares da Câmara, ou seja, $61 \%$ dos diplomados em cursos jurídicos, declararam ter outras ocupações. Desses, quatro dedicaram-se à carreira pública e somam a esta mais uma profissão: um delegado com formação em administração, dois procuradores que atuam como professores e um promotor ligado à área agropecuária. Os 83 restantes dividem-se em quatro grupos de acordo com a quantidade de ocupações declaradas: 56 deputados possuem mais de uma ocupação, 20 têm mais de duas, seis exercem mais de três e um deputado declarou possuir mais de quatro atividades, além do Direito e do mandato como representante. Dentre estas profissões, dos 87 deputados, 33 são professores, 23 são empresários, dez exercem atividades voltadas à agropecuária, seis são jornalistas e outros seis desempenham atividades de radialista. Existem ainda oito contadores e mais 36 outras ocupações.

Tais características podem ser visualizadas sob outro ângulo, na Tabela 5, na qual consta o percentual de bacharéis por partido político. Fica claro que todos os partidos políticos possuem em suas fileiras percentuais elevados destes profissionais. Desta forma, pode-se afastar a hipótese de haver uma única legenda que represente tal categoria profissional. O bacharel em Direito aparece de forma expressiva em todas as siglas partidárias com mais de 20 parlamentares. Em partidos com menor representação, é importante destacar o PL - Partido Liberal, cujos integrantes são majoritariamente empresários, economistas e administradores, não havendo, dentre seus nove parlamentares, nenhum diplomado em cursos jurídicos.

\section{TABELA 5}

Índices de Bacharéis em Direito nos Partidos com Mais de 20 Deputados Brasil - 1999

\begin{tabular}{lccc}
\hline Partidos & Deputados & Bacharéis & \% no Partido \\
\hline PFL & 109 & 34 & 31,2 \\
PSDB & 102 & 28 & 27,5 \\
PMDB & 101 & 29 & 28,7 \\
PT & 60 & 13 & 21,7 \\
PPB & 50 & 16 & 32,0 \\
PDT & 23 & 11 & 47,8 \\
PTB & 22 & 5 & 22,7 \\
\hline
\end{tabular}

Fonte: Site da Câmara dos Deputados na Internet (www.camara.gov.br).
Todos os partidos com mais de 20 deputados federais apresentam mais de um quinto de seus parlamentares formados em Direito. Esta característica não distingue os partidos de oposição daqueles de situação, uma vez que os dois principais partidos oposicionistas, PT e PDT, têm, respectivamente, o menor $(21,7 \%)$ e o maior $(47,8 \%)$ índice de deputados bacharéis em Direito. As três maiores legendas na Câmara mantêm, entre si, percentuais similares de acadêmicos com formação jurídica: $\operatorname{PFL~}(31,2 \%)$; PSDB $(27,5 \%)$; e PMDB $(28,7 \%)$. O PPB e o PTB também não apresentam nenhuma distorção com relação ao padrão dominante verificado nas demais siglas, com $32 \%$ e $22,7 \%$, respectivamente, de parlamentares formados em Direito.

Outra observação interessante a ser feita refere-se à quantidade de bacharéis por região do Brasil (Tabela 6). Dos 512 parlamentares, 143 são formados em Direito, o que corresponde a $27,9 \%$ do total. As três maiores regiões em termos de representação têm percentuais muito próximos da média nacional. No Sudeste, $29,8 \%$ de seus deputados são titulados em cursos jurídicos, no Nordeste, $30,4 \%$ e na região Sul, 28,6\%. O Centro-Oeste, região com o menor número de deputados federais (41) também apresenta um percentual próximo da média (29,3\%). A região Norte é a exceção à regra: dos seus 65 deputados, apenas dez, ou $15,4 \%$, são formados em Direito.

Especificando-se a análise, por unidade federativa, é possível desvendar a origem das informações que constam na Tabela 6 . O baixo índice indicado em relação à região Norte, por exemplo, explica-se pelo fato de que o Acre e o Amapá não possuem nenhum bacharel em Direito dentre seus 16 parlamentares. Acrescentam-se, ainda, a baixa proporção de diplomados em Direito encontrada em Roraima e Tocantins, com $12,5 \%$ e os índices inferiores a $30 \%$ nos demais estados. No caso do Sudeste, a distribuição mantém-se próxima a 30\%, com exceção de Minas Gerais, que registra um índice de 19,2\%. A região Sul apresenta casos muito desiguais: alcança seu ápice no Rio Grande do Sul (41,9\%) em contraste com Paraná $(16,7 \%)$. No Centro-Oeste verifica-se a maior das distorções regionais: enquanto em Brasília, entre seus oito deputados, nenhum é formado em Direito, no Mato Grosso do Sul, 50\% concluíram tal curso. Por fim, no Nordeste, com as exceções de Sergipe (25\%), Ceará (23\%) e Bahia $(21 \%)$, todos os demais estados apresentam taxas superiores a $30 \%$. O destaque, neste caso, fica por conta de Alagoas, com 55,6\%, o maior índice nacional de deputados federais bacharéis em Direito por estado. 
TABELA 6

Bacharéis em Direito na Câmara dos Deputados, segundo Regiões

Brasil - 1999

\begin{tabular}{lccc}
\hline Regiões & Deputados & Bacharéis & \% no Partido \\
\hline Brasil & $\mathbf{5 1 2}$ & $\mathbf{1 4 3}$ & $\mathbf{2 7 , 9 3}$ \\
Centro-Oeste & 41 & 12 & 29,27 \\
Nordeste & 151 & 46 & 30,46 \\
Norte & 65 & 10 & 15,38 \\
Sudeste & 178 & 53 & 29,78 \\
Sul & 77 & 22 & 28,57 \\
\hline
\end{tabular}

Fonte: Site da Câmara dos Deputados na Internet (www.camara.gov.br).

TABELA 7

Distribuição dos Bacharéis na Câmara, dos Cursos de Direito (1), dos Diplomados e da População, segundo Regiões Brasil - 1999

\begin{tabular}{lccrr} 
& & & \multicolumn{2}{c}{ Em porcentagem } \\
Regiões & $\begin{array}{c}\text { Bacharéis } \\
\text { na Câmara }\end{array}$ & $\begin{array}{c}\text { Cursos de } \\
\text { Direito }\end{array}$ & Diplomados & População \\
\hline Brasil & 100,0 & 100,0 & 100,0 & 100,0 \\
Centro-Oeste & 8,3 & 9,9 & 9,0 & 6,6 \\
Nordeste & 32,2 & 12,3 & 10,5 & 28,5 \\
Norte & 7,0 & 6,6 & 3,0 & 7,2 \\
Sudeste & 37,1 & 45,7 & 60,5 & 42,7 \\
Sul & 15,4 & 25,5 & 17,0 & 15,0 \\
\hline
\end{tabular}

Fonte: Sites: da Câmara dos Deputados, do Inep e do IBGE na Internet. (1) Relacionadas somente as instituições avaliadas pelo MEC no Provão de 1998.

A situação descrita anteriormente, salientando o aspecto regional, pode ser completada com a análise da Tabela 7, em que são apresentados os percentuais dos cursos jurídicos e da população. A região Norte registra equilíbrio entre o índice de bacharéis em Direito na Câmara (7,0\%), o percentual de cursos desta natureza avaliados em 1998 pelo MEC $(6,6 \%)$ e sua participação no total populacional $(7,2 \%)$. No entanto, responde por apenas $3 \%$ dos diplomados em 1998. Esta informação pode ajudar a explicar por que esta região possui baixo índice de deputados formados em Direito entre seus parlamentares (15,4\%). A região Centro-Oeste abriga 6,6\% da população do país, mas tem índices proporcionalmente altos de cursos de Direito $(9,9 \%)$, de diplomados $(9,0 \%)$ e de bacharéis na Câmara (8,3\%). Já a região Sul, apesar de contar com um quarto dos cursos jurídicos do Brasil, possui $15 \%$ da população do país, $15,4 \%$ dos bacharéis na Câmara e 17\% dos diplomados em 1998. Tal situação reflete a existência de um maior equilíbrio relativo entre demografia, diplomados e deputados formados em cursos jurídicos. $\mathrm{Na}$ região Sudeste, por sua vez, encontra-se o maior número proporcional destas escolas (45,7\%), de formados em 1998 $(60,5 \%)$ e da população do país $(42,7 \%)$. No entanto, seu percentual de bacharéis na Câmara é consideravelmente inferior aos demais índices $(37,1 \%)$. Por fim, no Nordeste, são observadas as maiores distorções dentre todas as regiões. Possui somente $12,3 \%$ dos cursos de Direito do Brasil, 10,5\% dos formados mas, em compensação, 28,5\% da população segundo informações da Fundação Instituto Brasileiro de Geografia e Estatística - IBGE para 1996 e 32,2\% dos bacharéis desta área existentes na Câmara.

Seria possível supor que, nas regiões consideradas mais atrasadas do país, existiria ainda uma grande valorização da figura do "doutor"? Ou seja, prevaleceria a crença segundo a qual teria maior capacidade política o cidadão com condições para concluir um curso superior, na maioria dos casos tradicional (medicina, engenharia e direito)? Este político estaria sendo visto, pela maioria, como um homem mais habilitado que os demais para o exercício das funções públicas? Apesar de não existir evidências empíricas suficientes para tentar responder a estas questões, é possível, no entanto, sugerir relações entre grau de desenvolvimento e prevalência de bacharéis em Direito. O Nordeste, por exemplo, formou apenas $10,5 \%$ destes bacharéis em 1998 e tem 32,2\% dos 143 deputados diplomados nesta área, atingindo um índice três vezes maior que o esperado. Esta tendência também é verificada na região Norte, onde se formaram 3,0\% dos estudantes em Direito de 1998, perfazendo um percentual duas vezes superior no número de bacharéis na Câmara $(7,0 \%)$. As regiões Sul e Sudeste, consideradas as mais desenvolvidas do país, apresentam índices negativos na análise relacionando formados na área e deputados titulados em Direito. Por fim, na região Centro-Oeste observa-se um equilíbrio nesta relação. É importante destacar que não se está afirmando peremptoriamente a existência de uma equivalência entre maior presença de advogados e atraso. Porém, dadas as evidências, pode-se sustentar que, nas regiões consideradas menos desenvolvidas, a presença de bacharéis em Direito é muito superior ao índice de alunos formados em comparação com as regiões consideradas mais avançadas.

Por fim, para completar esse retrato da Câmara e da Comissão para a Reforma do Judiciário, com foco especial nos bacharéis em Direito, será examinada a probabilidade destes supostos "técnicos" terem freqüentado escolas de qualidade.

O MEC - Ministério da Educação e Desporto - vem realizando nas faculdades de Direito, desde 1996, o exa- 
Os Bacharéis em Direito na Reforma do Judiciário: técnicos ou CURIOSOS?

me nacional de cursos ou "Provão". Tal avaliação tem por intuito quantificar as diferenças de qualidade existentes entre os mais de 200 cursos de Direito no Brasil com conceitos que variam do "A", para as melhores instituições, ao "E" para as piores. Certamente a utilização destes resultados é problemática, uma vez que a qualidade dos cursos pode ter sofrido alterações - para melhor ou para pior - da época em que os atuais parlamentares se formaram até o ano em que foi feita a avaliação do MEC. Além disso, é sabido que estes resultados podem apresentar sérias distorções. Ainda assim, a verificação das chances de um deputado proveniente de uma determinada região ter freqüentado uma boa escola pode fornecer mais alguns traços para o retrato que está sendo elaborado aqui. Assim, a partir da Tabela 8, verifica-se a probabilidade de se encontrar bons conhecedores de Direito entre os deputados, por região.

Segundo os dados da Tabela 8, não existiria possibilidade de a região Norte ter um bacharel proveniente de uma boa faculdade (conceito A ou B). No caso da região Nordeste, haveria $15,4 \%$ de chances de um diplomado ter estudado em uma instituição de alto nível. O Sudeste $(26,8 \%)$ e o Centro-Oeste $(23,8 \%)$ apresentam índices muito semelhantes de boas faculdades em Direito. Por fim, na região Sul, encontra-se o melhor coeficiente de bons cursos jurídicos, com 51,9\%. É importante ressaltar, uma vez mais, que este exercício baseia-se em pressupostos que podem não ocorrer necessariamente. Ou seja, um deputado de determinada região pode não ter estudado em uma faculdade localizada nos limites geográficos de seu estado. A Tabela 9 apresenta os totais de bacharéis por região na Comissão e, mediante a avaliação do MEC, a possibilidade destes serem provenientes de boas escolas.

\section{TABELA 8}

Distribuição dos Conceitos do MEC

Brasil - 1998

Em porcentagem

\begin{tabular}{lccc}
\hline Regiões & Conceito A - B & Conceito C & Conceito D - E \\
\hline Centro-Oeste & 23,8 & 23,8 & 52,4 \\
Nordeste & 15,4 & 34,6 & 50,0 \\
Norte & 0,0 & 28,6 & 71,4 \\
Sudeste & 26,8 & 46,4 & 24,7 \\
Sul & 51,9 & 38,9 & 9,3 \\
\hline
\end{tabular}

Fonte: Site do Inep na Internet (www.inep.gov.br).
TABELA 9

Bacharéis na Câmara e na Comissão e Probabilidade destes

Provirem de Boas Escolas

Brasil - 1999

\begin{tabular}{lccccc}
\hline Regiões & $\begin{array}{c}\text { Bacharéis na } \\
\text { Câmara }\end{array}$ & $\begin{array}{c}\% \\
\text { Cursos A-B }\end{array}$ & $\begin{array}{c}\text { Prováveis Bons } \\
\text { Bacharéis }\end{array}$ & $\begin{array}{c}\text { Bacharéis } \\
\text { na Comissão }\end{array}$ & Saldo \\
\hline Brasil & 143 & 100,0 & 35 & $\mathbf{2 8}$ & +7 \\
Centro-Oeste & 12 & 23,8 & 3 & 1 & +2 \\
Nordeste & 46 & 15,4 & 7 & 9 & -2 \\
Norte & 10 & 0,0 & 0 & 3 & -3 \\
Sudeste & 53 & 26,8 & 14 & 12 & +2 \\
Sul & 22 & 51,9 & 11 & 3 & +8
\end{tabular}

Fonte: Sites da Câmara dos Deputados e do Inep na Internet.

Dos 143 bacharéis em Direito existentes dentre os deputados federais, 28 fazem parte da Comissão para reforma do Judiciário. Segundo o índice obtido da relação entre o percentual de bons cursos por região e o número de titulados na Câmara, seria possível preencher estas 28 vagas ( $90 \%$ da Comissão) com bacharéis provenientes de boas escolas. A probabilidade da existência de bons acadêmicos é tão grande que seria viável, inclusive, a ocupação das 31 cadeiras da Comissão com "técnicos" no saber jurídico, tal como idealizava a declaração do presidente da Câmara. No entanto, para que tal condição ocorresse, teria, por exemplo, de ser feita uma cuidadosa divisão regional desses cargos, o que significaria, inclusive, a antidemocrática exclusão de deputados de uma região do quadro de parlamentares componentes da referida Comissão. Uma análise mais detalhada da Tabela 9 revela situações distintas entre as regiões, diminuindo as chances da Comissão ser plenamente composta por "bons" bacharéis em Direito. A região Norte, por exemplo, não apresenta bons cursos jurídicos e, conseqüentemente, é baixa a probabilidade de contar com "bons" bacharéis dentre os seus três parlamentares nomeados. As regiões Sul, Sudeste e Centro-Oeste têm alta probabilidade de contar com profissionais competentes na Comissão, uma vez que apresentam saldo positivo na relação "prováveis bons bacharéis" e "número de bacharéis na Comissão". Por fim, a região Nordeste tem um déficit de dois parlamentares e, de acordo com este exercício, estaria colaborando, a exemplo da região Norte, para a diminuição da qualidade dos chamados "técnicos".

Mesmo sendo a Comissão para reforma do Poder Judiciário formada a partir de uma lógica que garante, inclusive, representatividade para todas as regiões do país, é possível supor que os bacharéis em Direito que a com- 
põem são, de uma maneira geral, bons conhecedores do assunto. Excetuando-se os cinco parlamentares que provavelmente não provêm de boas escolas - três da região Norte e dois do Nordeste - restariam 23 possíveis bons bacharéis, ou seja, $82 \%$ do total de diplomados em cursos jurídicos, ou $74 \%$ da Comissão. Tal resultado, certamente, auxiliaria na confirmação do argumento sustentado pelo presidente da Câmara.

\section{NOTAS FINAIS: UMA COMISSÃO DE “TÉCNICOS”}

Os dados apresentados possibilitam algumas conclusões a respeito da presença dos diplomados em cursos jurídicos na Câmara dos Deputados. Chama especialmente a atenção o fato de os bacharéis em Direito ainda comporem o maior grupo profissional nesta Casa Legislativa. Embora tenham perdido o prestígio que gozavam no passado, constituem um grupo de referência. Os termos do debate entre os presidentes da Câmara e do Senado, de alguma forma, centra-se nas possíveis qualidades que singularizariam os bacharéis. Desta forma, apesar de ser claramente decrescente a presença de advogados, a posse desta qualificação profissional parece ainda justificar sua participação em determinadas Comissões. E este foi o entendimento que prevaleceu entre os deputados federais quando se tratou de formar a Comissão responsável pela elaboração de emendas para a reforma do Poder Judiciário.

Bacharéis são encontrados em todos os partidos políticos, não havendo uma agremiação específica que represente a corporação dos advogados ou que exerça o monopólio na atração política desta categoria profissional. Todas as legendas com mais de 20 parlamentares têm índices elevados de bacharéis em Direito em suas bancadas. Exercendo, em sua maioria, outras atividades, parece correto pensar que a eleição de muitos destes profissionais não está exclusivamente vinculada ao diploma jurídico. Outros meios de contato com o eleitorado parecem ter operado. Esta tese encontra apoio na expressiva presença de bacharéis-radialistas, bacharéis-jornalistas, bacharéis-professores e bacharéis-empresários que conquistaram uma cadeira na Câmara. Não se observa também nenhum tipo de viés regional relacionado à presença de tais parlamentares. Todas as regiões do Brasil, apesar das distorções verificadas, possuem proporções consideráveis de representantes formados em cursos jurídicos.
E a reforma do Judiciário? Seria este tema, afinal, matéria para advogados ou para todos aqueles que ali estão representando o interesse dos mais diversos segmentos sociais? O problema contrapondo advogados e os chamados "curiosos" poderia ter tantas soluções quantas são as teorias sobre o papel da representação democrática. $\mathrm{O}$ presidente da Câmara, defendendo a participação exclusiva de advogados, demonstrou abraçar uma peculiar forma de atuação legislativa. Os dados apresentados mostram que o deputado Michel Temer (PMDB-SP) não estava sozinho. Ao contrário, sob a ótica de todos os partidos, a reforma do Judiciário, pelo menos no que se refere às qualificações profissionais do grupo encarregado de propor as emendas, é matéria para "técnicos" no assunto e não para "curiosos".

Restaria saber, no entanto, se a reforma do Judiciário é uma questão técnica e que, como tal, só poderia ser tratada por técnicos do saber jurídico, que, exercendo seu saber, chegariam a uma solução "ótima", inteiramente desprovida de interesses e paixões. Os embates travados desde que o tema foi colocado em discussão contrariam este suposto. A dissensão entre os operadores do direito e internos a cada um dos diferentes grupos - magistrados, promotores, procuradores, defensores públicos, delegados, juristas e advogados -, é razão mais do que suficiente para se contestar o suposto segundo o qual os "técnicos no saber Jurídico" possuiriam uma especial capacidade para a formulação de uma reforma. Obviamente não se está minimizando a importância de um saber especializado, mas sim evocando um princípio democrático que não pode ser olvidado: a legitimidade dos diferentes interesses. Por outra parte, a experiência indica que uma Justiça mais condizente com uma sociedade moderna e que se pretende democrática sempre encontrará na tecnicidade do Direito saídas adequadas aos interesses em jogo. Finalmente, o tamanho do caminho a ser percorrido para a efetivação de mudanças, as dificuldades a serem superadas e se os parlamentares escolhidos atenderão à demanda nacional por uma Justiça apta a dar respostas mais ágeis e eficientes são questões que certamente exigirão a consideração de variáveis não dedutíveis da formação profissional.

\section{NOTAS}

1. No que diz respeito a estes dois meios para se alterar a Constituição Revisão Constitucional e Proposta de Emenda Constitucional -, destaque-se a diferença quanto aos procedimentos para a aprovação de mudanças. No caso da Revisão Constitucional, segundo determinavam as próprias disposições transitórias do texto aprovado em 1988, tem-se um processo de tomada de 
Os BacharéIS EM DiReIto NA REFORMa do Judiciário: TÉCNICOS OU CURIOSOS?

decisões muito mais fácil e ágil do que aquele que regula os processos regulares de alterações na Constituição. No período de revisão constitucional, as modificações na Lei Maior requeriam apenas maioria absoluta no Congresso, reunido em sessão unicameral. Para a aprovação de uma emenda, em contraste, é necessário uma maioria qualificada de três quintos dos membros de cada Casa, em dois turnos de votação.

2. Joaquim Falcão (1984:24) argumenta que este controle era ferrenho, "nem o Ato Adicional de 1834, que transferiu grande soma de poderes para as províncias o alterou (...) [Havia] o controle dos recursos, do currículo, do método de ensino, da nomeação dos lentes, do diretor, dos programas e até dos compêndios".

3. Para um relato das discussões que precederam a criação das faculdades de Direito no país, ver Simões Neto (1983).

4. Informações obtidas no site do Inep (www.inep.gov.br) Instituto Nacional de Estudos e Pesquisas Educacionais.

5. Sublinhe-se que o Estado de São Paulo não é uma exceção daquilo que se passa no país. Dados de 1969 indicam que as Faculdades de Direito eram freqüentadas por 60.525 estudantes. Apenas dez anos depois, em 1979, este número praticamente dobrou, passando para 127.414

6. A OAB foi criada na década de 30 , com a finalidade de representar e defender os interesses da corporação.

7. Calcula-se que, em média, $80 \%$ dos inscritos nos exames de seleção para a magistratura e para o Ministério Público são reprovados.

8. Um dos "cursinhos" mais procurados de São Paulo cobra mensalidades que variam de $\mathrm{R} \$ 300,00$ a $\mathrm{R} \$ 360,00$, segundo dados de pesquisa feita em julho de 1999.
9. Sobre as diferentes posições ideológicas destes partidos, ver Kinzo (1993).

\section{REFERÊNCIAS BIBLIOGRÁFICAS}

BRUNO, E.S. História e tradições da cidade de São Paulo. Rio de Janeiro, Livraria José Olímpio Editora, 1953.

CARVALHO, J.M. de. Elite and state building in imperial Brazil. Phd thesis. Stanford University, 1974.

CASTRO, R. de "O advogado e a sociedade". Folha de S.Paulo. São Paulo, $11 / 08 / 99$.

FALCÃO, J. Os advogados: ensino jurídico e mercado de trabalho. Recife, Fundação Joaquim Nabuco, Editora Massangana, 1984.

KINZO, M.D.G. Radiografia do quadro partidário brasileiro. São Paulo, Fundação Kaonrad-Adenauer-Stiftung, 1993.

MAGAlHÃES, A.C. O Estado de S. Paulo. São Paulo, 15/06/1999.

PINHEIRO, A.C. Judicial system performance and economic development. Rio de Janeiro, BNDES, 1996.

SIMÕES NETO, F.T. Os bacharéis na política e a política dos bacharéis. Tese de Doutorado em Ciência Política. São Paulo, FFLCH/USP, 1983.

TEMER M. O Estado de S. Paulo. São Paulo, 15/06/1999. 